\title{
Strength of the respiratory and lower limb muscles and functional capacity in chronic stroke survivors with different physical activity levels
}

\author{
Janaine C. Polese, Marina B. Pinheiro, Christina D. C. M. Faria, \\ Raquel R. Britto, Verônica F. Parreira, Luci F. Teixeira-Salmela
}

\begin{abstract}
Background: The assessment of strength and its relationships with functional capacity could contribute to more specific and effective disability management of stroke survivors. Objective: To compare and investigate associations between measures of strength and functional capacity of 98 chronic stroke survivors, stratified into three groups, according to their physical activity levels. Method: The physical activity levels were classified as impaired, moderately active, and active, based on their Human Activity Profile (HAP) scores. Strength was assessed by the maximal inspiratory (MIP) and expiratory (MEP) pressures and by the residual deficits (RDs) of work of the lower limb and trunk muscles, whereas functional capacity was evaluated by the distance covered during the six-minute walking test (6MWT). Results: One-way analyses of variance revealed significant differences between the groups, except between the active and moderately active groups regarding the RDS of the hip and knee flexors/extensors and ankle dorsiflexors $(2.91<\mathrm{F}<8.62 ; 0.001<\mathrm{p}<0.01)$. Differences between the groups were found for the 6MWT $(\mathrm{F}=10.75 ; \mathrm{p}<0.001)$, but no differences were found for the MIP and MEP measures $(0.92<\mathrm{F}<2.13 ; 0.13<\mathrm{p}<0.40)$. Significant, negative, and fair correlations were observed between the RDS of the hip and knee muscles and the 6MWT $(0.30<\mathrm{r}<-0.43$; p $<0.01)$ and the HAP $(-0.28<\mathrm{r}<-0.41$; $\mathrm{p}<0.01)$. Moderate to good correlations were found between the 6MWT and the HAP $(\mathrm{r}=0.50 ; \mathrm{p}<0.0001)$. There were no significant correlations between measures of respiratory strength and any of the investigated variables $(-0.11<\mathrm{r}<0.12$; $0.26<\mathrm{p}<0.56)$. Conclusions: Lower strength deficits and higher functional capacity were associated with higher physical activity levels. However, the moderately active and active groups demonstrated similar strength deficits.
\end{abstract}

Keywords: stroke; respiratory muscles; muscular weakness; exercise capacity; physical activity levels; rehabilitation.

\section{HOW TO CITE THIS ARTICLE}

Polese JC, Pinheiro MB, Faria CDCM, Britto RR, Parreira VF, Teixeira-Salmela LF. Strength of the respiratory and lower limb muscles and functional capacity in chronic stroke survivors with different physical activity levels. Braz J Phys Ther. 2013 SeptOct; 17(5):487-493. http://dx.doi.org/10.1590/S1413-35552012005000114

\section{Introduction}

The physical consequences of stroke are variable and may include impairments in the motor, emotional, and sensory systems, language, perception, and cognitive functions ${ }^{1}$. Hemiparesis, the most frequently observed motor deficit, affects more than $80 \%$ of these individuals $^{2}$ and is related to decreased exercise capacities and physical function ${ }^{3}$. Clinically, muscular weakness has been recognized as a limiting factor in the motor rehabilitation of stroke patients and as the most contributing factor to post-stroke disabilities ${ }^{4}$. Therefore, strengthening exercises have been widely employed to increase functional capacity in individuals with hemiparesis $\mathrm{s}^{5-8}$. However, further studies are required to investigate other variables, which could interfere with functional capacities with this population.

Previous studies have reported decreased respiratory strength in individuals during both the acute and chronic post-stroke stages ${ }^{9-12}$. Within this context, weaknesses of the respiratory muscles and changes in the thoraco-abdominal motion could be related to decreased tidal volumes, and consequently, lower exercise tolerance, as observed in healthy individuals ${ }^{13}$. Additionally, in accordance with Patterson et al. ${ }^{14}$, the ability to generate force with the paretic lower limb is the major determinant of the ability to perform short or long walks.

The preventive and rehabilitative approaches of individuals with hemiparesis are of utmost relevance due to the increased survival rates of this population ${ }^{15}$. Thus, to assess muscular parameters of individuals with chronic hemiparesis and its relationships with functional capacities could contribute to a more specific management of this condition. Therefore, the aim of this study was to compare motor performance measures (strength of the respiratory and lower limb 
muscles) and functional capacity, as assessed by the distance walked during the six-minute walk test (6MWT), between individuals with hemiparesis with various levels of physical activity. In addition, it investigated possible associations between motor parameters and functional capacities in individuals with chronic hemiparesis. It was hypothesized that subjects with chronic stroke who had higher levels of physical activity would demonstrate higher levels of functional capacity and lower strength deficits of the respiratory and lower limb muscles.

\section{Method}

\section{Participants}

Ninety-eight subjects with unilateral stroke, who had residual weakness and/or spasticity of the affected lower extremity, were recruited on a volunteer basis from the general community of Belo Horizonte, MG, Brazil. All participants were screened to ensure that their mean time since the onset of the stroke was at least nine months; were above 20 years of age; were able to walk with or without assistive devices; had no facial palsy which could prevent proper labial occlusion during tests; and had no cognitive impairments, as assessed by the Mini Mental State Examination ${ }^{16}$, according to the cut-off scores recommended by Brucki et al. ${ }^{17}$. They should also be able to understand and perform all of the test procedures. Those individuals with non-strokerelated disabilities and who had respiratory diseases were excluded. All participants provided consent based upon approval by the Ethical Review Board of Universidade Federal de Minas Gerais (UFMG), Belo Horizonte, MG, Brazil (protocol 172/02).

\section{Instruments and procedures}

Initially, the participants underwent a physical examination and an interview for the collection of anthropometric, demographic, and clinical data, such as age, gender, body mass, height, time since the onset of stroke, paretic side, and the use of medications. The participants were stratified into three groups based upon their physical activity levels, which were determined by the self-reported activity scores on the Brazilian version of the Human Activity Profile (HAP), which is considered a valid and reliable tool $^{18}$. The participants' physical activity levels were classified according to their adjusted activity scores (AAS) either as impaired $(<53)$, moderately active (53-74) or active $(>74)^{19}$.

\section{Lower limb muscular strength}

Bilateral measures of strength of the major muscular groups of the ankle, knee, and hip joints were obtained with the Biodex System 3Pro ${ }^{\circledR}$ isokinetic dynamometer (Biodex Medical System Inc., Shirley, NY) in the concentric-concentric mode at angular speeds of $60 \%$ s. Isokinetic measures have shown to be reliable for evaluating the strength of individuals with hemiparesis ${ }^{20,21}$ and all procedures were carried out following previously described protocols $^{8,21}$. The residual deficits (RDs) of the normalized work measures, in Joules, were used for analyses and were calculated according to the following formula: 100 - (paretic/non-paretic lower limb *100).

\section{Six-minute walk test}

The distances covered during the 6MWT, which appropriately reflect the physical capacity to perform daily tasks, were registered for analyses ${ }^{22-24}$. The test was carried out, following the procedures and recommendations of the American Thoracic Society ${ }^{25}$, which were adapted to the Brazilian Portuguese language ${ }^{26}$.

\section{Respiratory muscular strength}

Respiratory strength was evaluated by measures of maximal inspiratory (MIP) and expiratory (MEP) pressures, which were obtained by a previously calibrated manovacuometer with operating intervals of $\pm 300 \mathrm{cmH}_{2} \mathrm{O}\left(\mathrm{GeRar}^{\circledR}\right.$, São Paulo, Brazil). All of the test procedures were conducted according to previous recommendations $\mathrm{s}^{27,28}$. These measures have shown adequate psychometric properties in previous studies $^{29,30}$.

\section{Statistical analysis}

Descriptive statistics, tests for normality (Kolmogorov-Smirnov), and equality of variances (Levene) were carried out for all outcome variables. One-way analyses of variance (ANOVAs) followed by LSD post-hoc tests were employed to investigate differences between the groups (impaired, moderately active, and active) regarding the RDs of the paretic lower limb muscles, the distances covered during the 6MWT, and the respiratory pressures. Pearson correlation coefficients were calculated to explore the relationships between these selected variables and were classified as low or none $(0.00<r<0.25)$, fair $(0.25<r<0.50)$, moderate to good $(0.50<r<0.75)$, and good to excellent $(r>0.75)^{31}$. All analyses were carried out with the SPSS software package (Version 17.0) with a significance level of 5\%. 


\section{Results}

\section{Participants' characteristics}

Ninety-eight individuals, 54 men and 44 women, participated in this study. They had a mean age of $56.4 \pm 12.5$ years and a time since the onset of stroke ranging from six to 240 months. No significant differences between the three physical activity level groups were observed regarding the participants' ages and the time since the onset of stroke ( $p=0.84$ and $p=0.68$, respectively). Their clinical, demographic, and anthropometric data are described in Table 1.

Six individuals were unable to perform the respiratory pressure procedures (four of the impaired and two of the moderately active group) and the isokinetic work data of eight individuals were excluded due to technical problems (two of the impaired, six of the moderately active, and one from the active group). Strength data for the ankle plantar and dorsal flexor muscles were obtained for only 40 individuals (four from the impaired, 25 from the moderately active, and 11 from the active group), since 58 participants were unable to generate enough torque to perform the tests.

\section{Comparisons between the groups}

Table 2 provides the results of the between-group comparisons for all of the variables. No significant differences between the groups were observed for the RDs of the ankle plantar flexor muscles $[F(2$, $37)=0.67 ; p=0.52]$. However, for all the other muscular groups, significant differences between the groups were found, except between the moderately

Table 1. Demographic and anthropometric characteristics of the participants.

\section{Characteristic}

Age (years), mean $\pm \mathrm{SD}$, (range: min-max)

Gender, male, n (\%)

Paretic side, right, $\mathrm{n}(\%)$

Time since the onset of stroke (months), mean $\pm \mathrm{SD}$, (range: min-max)

Use of medications (number), mean \pm SD

BMI $\left(\mathrm{Kg} / \mathrm{m}^{2}\right)$, mean $\pm \mathrm{SD}$, (range: $\left.\min -\max \right)$ $n=98$

$56.4 \pm 12.5(24-86)$

$54(55)$

58 (59)

$64.8 \pm 53.6(6-240)$

$3 \pm 2$

$25.9 \pm 4(15.24-36.51)$

$\mathrm{SD}=$ Standard deviation; BMI= Body Mass Index.

Table 2. Demographic and clinical data (means \pm standard deviations and range [minimum-maximum] of the participants, according to their physical activity levels and comparisons between the groups.

\begin{tabular}{|c|c|c|c|c|}
\hline Variable & Impaired $(n=26)$ & $\begin{array}{l}\text { Moderately active } \\
\qquad(n=55)\end{array}$ & Active $(n=17)$ & Total $(n=98)$ \\
\hline $\begin{array}{l}\text { Time since the onset of } \\
\text { stroke (months) }\end{array}$ & $74.4 \pm 69.8^{\mathrm{a}}(6-240)$ & $60.9 \pm 46.4^{\mathrm{a}}(6$ & $63.5 \pm 51.1^{\mathrm{a}}(15-180)$ & $64.8 \pm 53.6(6-240)$ \\
\hline Age (years) & $56.4 \pm 12.5^{\mathrm{a}}(29-86)$ & $55.7 \pm 12.0^{\mathrm{a}}(24-79)$ & $57.8 \pm 14.2^{\mathrm{a}}(26-82)$ & $56.4 \pm 12.5(24-86)$ \\
\hline MIP (cmH2O) & $65.1 \pm 33.4^{\mathrm{a}}(20-150)$ & $73.6 \pm 24.3^{\mathrm{a}}(30-130)$ & $84.7 \pm 35.6^{\mathrm{a}}(30-150)$ & $73.5 \pm 29.2(20-150)$ \\
\hline MEP (cmH2O) & $73.9 \pm 35.4^{\mathrm{a}}(20-140)$ & $82.1 \pm 34.1^{\mathrm{a}}(30-200)$ & $90.3 \pm 49.9^{\mathrm{a}}(25-190)$ & $81.6 \pm 37.7(20-200)$ \\
\hline RD hip flexion (\%) & $34.6 \pm 23.8^{\mathrm{a}}(-25-71)$ & $21.3 \pm 24.6^{\mathrm{b}}(-23-100)$ & $10.6 \pm 24.9^{\mathrm{b}}(-56-46)$ & $22.6 \pm 25.3(-56-100)$ \\
\hline RD hip extension (\%) & $55.2 \pm 50.1^{\mathrm{a}}(-101-100)$ & $20.4 \pm 70.9^{\mathrm{b}}(-322-100)$ & $13.5 \pm 35.9^{\mathrm{b}}(-26-100)$ & $27.7 \pm 62.1(-322-100)$ \\
\hline RD knee flexion (\%) & $72.4 \pm 39.5^{\mathrm{a}}(-48-100)$ & $52.5 \pm 40.8^{\mathrm{b}}(-47-100)$ & $32.9 \pm 24.1^{\mathrm{b}}(-13-74)$ & $53.6 \pm 40.4(-48-100)$ \\
\hline RD knee extension (\%) & $53.5 \pm 23.1^{\mathrm{a}}(-12-87)$ & $33.4 \pm 28.6^{\mathrm{b}}(-30-90)$ & $19.4 \pm 27.5^{\mathrm{b}}(-25-77)$ & $36.0 \pm 29.6(-30-90)$ \\
\hline RD plantar flexion (\%) & $51.8 \pm 49.7^{\mathrm{a}}(-7-95)$ & $29.0 \pm 73.1^{\mathrm{a}}(-159-100)$ & $52.2 \pm 15.8^{\mathrm{a}}(28-72)$ & $36.9 \pm 60.0(-159-100)$ \\
\hline RD dorsiflexion (\%) & $-190.0 \pm 216.8^{a}(-433-18)$ & $0.1 \pm 68.5^{\mathrm{b}}(-209-100)$ & $10.3 \pm 21.4^{b}(-26-35)$ & $-11.3 \pm 91.1(-433-100)$ \\
\hline 6MWT (m) & $267.7 \pm 118.3^{\mathrm{a}}(40-454)$ & $368.4 \pm 124.4^{b}(61-674)$ & $440.7 \pm 107.0^{c}(220-650)$ & $356.6 \pm 132.2(40-674)$ \\
\hline
\end{tabular}

$\mathrm{BMI}=$ Body Mass Index; MIP= maximal inspiratory pressure; $\mathrm{MEP}=$ maximal expiratory pressure; $\mathrm{RD}=$ residual deficit; $6 \mathrm{MWT}=$ distance covered during the six-minute walk test. For each row, different letters represent statistically significant differences between groups ( $\mathrm{p}<0.05$ ). 
active and active groups $(4.91<F(2,89)<8.62$; $0.01<p<0.001)$. As illustrated in Figure 1, the RDS of the hip flexor muscles demonstrated a tendency for lower values with higher physical activity levels, although no significant differences between the moderately active and the active groups were observed. Similar patterns were found for the RD values for all of the other muscular groups.

Significant between-group differences were observed for the distance covered during the 6MWT $[F(2,95)=10.75 ; p<0.001]$. However, no significant differences between the groups were found for the MIP $[F(2,91)=2.13 ; p=0.13]$ and $\operatorname{MEP}[F(2$, 91) $=0.92 ; p=0.40]$ measures.

\section{Associations between the variables}

Significant, negative, and fair correlations were found between the RDs of all the lower limb muscles, except for the ankle plantar and dorsal flexors, with the distance covered during the $6 \mathrm{MWT}(-0.30<r<-0.43$; $p<0.01)$ and the AAS scores $(-0.28<r<-0.41$; $p<0.01)$. These associations indicated that the higher the work differences between the paretic and nonparetic lower limbs, as expressed by the RDs, the lower were the AAS score and the distances covered during the 6MWT. In addition, moderate to good correlations between the distances covered during the $6 \mathrm{MWT}$ and the AAS scores were also found $(r=0.51$; $p<0.0001)$. It is important to note that no significant correlations were found between the respiratory strength measures and any of the other investigated variables $(-0.11<r<0.12 ; 0.26<p<0.56)$.

\section{Discussion}

The present study found significant differences between the groups regarding the functional capacities and the RDs of the paretic lower limb

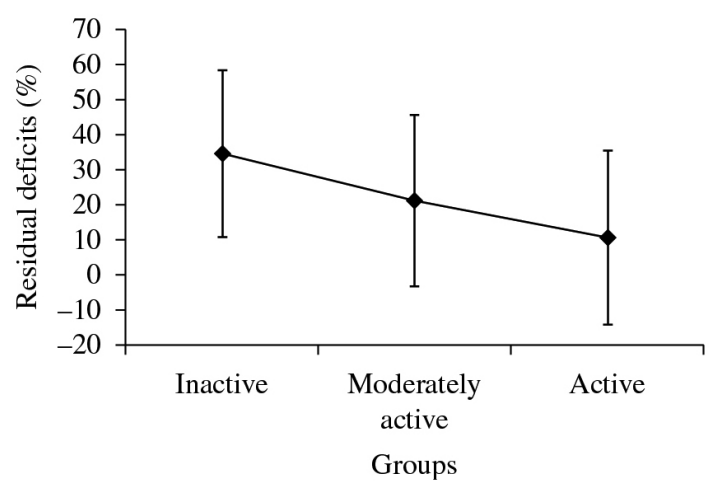

Figure 1. Residual deficits of the hip flexor muscles (means and standard deviations) for the impaired, moderately active, and active groups. muscles. However, regarding the RD, no significant differences were found between the moderately active and active groups. No significant between-group differences were found for the respiratory strength measures. Significant correlations were found between the RDs of the hip and knee muscles, the functional capacity, and the physical activity levels. Interestingly, no significant correlations were found between the measures of respiratory strength and any of the investigated variables.

To the best of our knowledge, this was the first study to examine the relationships between the strength of the respiratory and the lower limb muscles and the distances covered during the 6MWT in individuals with chronic hemiparesis based upon their physical activity levels. It is reported that little attention is given to the pulmonary system during the evaluation and treatment of individuals with hemiparesis, although it is known that these individuals demonstrate deficits in this system ${ }^{32}$. Interestingly, there were no significant correlations between the respiratory strength measures and any of the other studied variables, nor differences in respiratory strength between the impaired, moderately active, and active groups.

Differences between the impaired, moderately active, and active groups were found for all work measures, except for the ankle plantarflexor muscles, demonstrating that individuals with higher levels of physical activity showed fewer strength discrepancies between their paretic and non-paretic lower limbs. Interestingly, the work measures were not different between the moderately active and active groups. These findings could be partially explained by the high levels of inter-subject variability, as evidenced by the high standard deviation values found for all groups. The RDs of the work measures were used for analyses, since their calculations are based upon the principle that the performance of the non-paretic lower limb of each individual was the reference for the performance of the paretic one. Thus, the use of this variable allows objective comparisons between groups and reduces the typical variability of the results in this population, which facilitates the interpretation of the findings ${ }^{33}$. However, the variability of the results still remained high, but this finding seems common with this population, when motor and functional parameters are investigated $\mathrm{d}^{8,11,34,35}$.

Although previous studies have reported that the variable which best explained physical activity levels was walking speed ${ }^{36}$, and that plantar flexor strength has been identified as an important component of speed $^{37}$, the work produced by the ankle plantar flexor 
muscles was the only variable which did not show differences between the groups. However, only 40 individuals were able to perform the ankle tests and this may have influenced the results, in addition to the high inter-subject variability.

Most of the RD values did not show regular distribution patterns since some individuals showed positive values and others negative ones, which meant that in these cases, the paretic side was able to produce higher levels of work than the non-paretic one. Stabilization has been reported to be an important factor influencing the amount of muscular force produced during testing ${ }^{38-40}$. Although stabilization was performed following the manufacturer's recommendations, perhaps the paretic limbs received greater stabilization from the non-paretic side, which could have contributed to the higher values found in the same muscles on the paretic side, compared to the non-paretic one, and could partially explain the negative values.

The RD levels of the isokinetic work generated by the lower limb muscles were selected to demonstrate muscular performance. Despite the fact that peak torque is considered an excellent indicator of maximum levels of forces that an individual is able to generate, this variable alone does not take into account the ability of maintaining this force over a certain range of motion. Work, on the other hand, demonstrates the ability of individuals to generate and sustain forces over a certain range of motion ${ }^{41}$. This fact might explain the fair correlations found between the isokinetic work and the distance covered during the 6MWT.

Despite reports that individuals with hemiparesis show significant respiratory dysfunctions and reduced exercise tolerance ${ }^{42}$, the present findings do not support the idea that individuals with various exercise capacities show differences in strength in their respiratory muscles. These findings could be partially explained by the fact that the included individuals had chronic hemiparesis and were probably already functionally adapted and did not demonstrate major respiratory strength deficits ${ }^{11}$. However, Sutbeyaz et al. ${ }^{32}$ showed that a six-week strengthening program of the inspiratory muscles was able to increase exercise capacity, decrease dyspnea, and improve the quality of life in individuals with hemiparesis who demonstrated greater respiratory strength deficits.

The absence of significant relationships between measures of respiratory strength and the distance covered during the $6 \mathrm{MWT}$, could be related to the distinct demands required for the measurement of these variables. The manovacuometry, for instance, requires maximum effort over a short period of time, whose demands are not equivalent to those required for the execution of the 6MWT, in which the individual should maintain efforts throughout the test.

The significant differences between the groups regarding the distance covered during the 6MWT suggested that active individuals had higher physical capacities, corroborating previous reported findings with the elderly ${ }^{26}$. From the functional point of view, the 6MWT is widely used for the evaluation of physical fitness and exercise capacity with various populations ${ }^{43}$ and consists of a simple and practical test, that can be widely used within clinical contexts. Moderate correlations were observed between the distances covered during the 6MWT and the AAS, which demonstrated that they assessed similar aspects.

It was observed that individuals with higher activity levels, as determined by their AAS scores, also had higher levels of functional capacity, as demonstrated by the greater distances covered during the 6MWT. Previous studies reported that individuals with hemiparesis have reduced abilities to exercise and showed a $40 \%$ reduction in their exercise capacities, compared to sedentary healthy individuals, matched by age and sex ${ }^{32}$. These findings show the importance of maintaining high physical activity levels for this population.

It should be noted that due to the design of the study, causal relationships cannot be determined. In addition, the fact that the sample size was also not uniformly distributed between the groups may have influenced the results. It is important to point out that only individuals with chronic hemiparesis who demonstrated the ability to independently walk were included. Thus, the present findings cannot be generalized to subjects with different characteristics, such as being in the acute or sub-acute stages or being unable to walk. Furthermore, parameters related to the cardiovascular system were not taken into consideration and they may have influenced the assessments, especially the 6MWT. This aspect should be investigated in future studies.

\section{Conclusions}

The findings of this study demonstrated that individuals with hemiparesis with different physical activity levels showed differences in the distance walked during the 6MWT and work deficits of the paretic lower limb muscles. However, differences in strength were not found only between the moderately 
active and active groups. Measures of respiratory strength were similar between the groups, and these variables were not related to any of the other functional variables. Lower strength deficits and higher functional capacities were associated with higher physical activity levels.

\section{- Acknowledgements}

To the Brazilian national funding agencies, Coordenação de Aperfeiçoamento de Pessoal de Nível Superior (CAPES), Conselho Nacional de Desenvolvimento Científico e Tecnológico (CNPQ), and Fundação de Amparo a Pesquisa do Estado de Minas Gerais (FAPEMIG).

\section{References}

1. Kelly-Hayes PM, Robertson JT, Broderick JP, Duncan PW, Hershey LA, Roth EJ, et al. The American Heart Association Stroke outcome classification. Stroke. 1998;29(6):1274-1280. PMid:9626308. http:// dx.doi.org/10.1161/01.STR.29.6.1274

2. LeBrasseur NK, Sayers SP, Ouellette MM, Fielding RA. Muscle impairments and behavioral factors mediate functional limitations and disability following stroke. Phys Ther. 2006;86(10):1342-50. PMid:17012638. http:// dx.doi.org/10.2522/ptj.20050162

3. Billinger SA, Coughenour E, MacKay-Lyons MJ, Ivey FM. Reduced Cardiorespiratory fitness after stroke: Biological consequences and exercise-induced adaptations. Stroke Res Treat. 2012;2012:1-11. PMid:21876848 PMCid:PMC3159380. http://dx.doi. org/10.1155/2012/959120

4. Canning CG, Ada L, Adams R, O’Dwyer NJ. Loss of strength contributes more to physical disability after stroke than loss of dexterity. Clin Rehabil. 2004;18(3):300-8. PMid:15137561. http://dx.doi. org/10.1191/0269215504cr715oa

5. Hill TR, Gjellesvik TI, Moen PM, Torhaug T, Fimland MS, Helgerud J, et al. Maximal strength training enhances strength and functional performance in chronic stroke survivors. Am J Phys Med Rehabil. 2012;91(5):393400. PMid:22357133. http://dx.doi.org/10.1097/ PHM.0b013e31824ad5b8

6. Ouellette MM, LeBrasseur NK, Bean JF, Phillips E, Stein J, Frontera WR, et al. High-intensity resistance training improves muscle strength, self-reported function, and disability in long-term stroke survivors. Stroke. 2004;35(6):1404-9. PMid:15105515. http://dx.doi. org/10.1161/01.STR.0000127785.73065.34

7. Olney SJ, Nymark J, Brouwer B, Culham E, Day A, Heard $\mathrm{J}$, et al. A randomized controlled trial of supervised versus unsupervised exercise programs for ambulatory stroke survivors. Stroke. 2006;37(2):476-81. PMid:16410482. http://dx.doi.org/10.1161/01.STR.0000199061.85897.b7
8. Teixeira-Salmela LF, Olney SJ, Nadeau S, Brouwer B. Muscle strengthening and physical conditioning to reduce impairment and disability in chronic stroke survivors. Arch Phys Med Rehabil. 1999;80:1211-1218. http://dx.doi. org/10.1016/S0003-9993(99)90018-7

9. Harraf F, Ward K, Man W, Rafferty G, Mills K, Polkey $\mathrm{M}$, et al. Transcranial magnetic stimulation study of expiratory muscle weakness in acute ischemic stroke. Neurology. 2008;71(24):2000-7 PMid:19064882. http:// dx.doi.org/10.1212/01.wnl.0000336927.30977.56

10. Lanini B, Bianchi R, Romagnoli I, Coli C, Binazzi B, Gigliotti F, et al. Chest wall kinematics in patients with hemiplegia. Am J Respir Crit Care Med. 2003;168(1):109 13. PMid:12714347. http://dx.doi. org/10.1164/rccm.200207-745OC

11. Teixeira-Salmela LF, Parreira VF, Britto RR, Brant TC, Inacio EP, Alcantara TO, et al. Respiratory pressures and thoracoabdominal motion in communitydwelling chronic stroke survivors. Arch Phys Med Rehabil. 2005;86(10):1974-8. PMid:16213241. http:// dx.doi.org/10.1016/j.apmr.2005.03.035

12. Ward K, Seymour J, Steier J, Jolley CJ, Polkey MI, Kalra $\mathrm{L}$, et al. Acute ischaemic hemispheric stroke is associated with impairment of reflex in addition to voluntary cough. Eur Respir J. 2010;36(6):1383-90. PMid:20413536. http:// dx.doi.org/10.1183/09031936.00010510

13. Harik-Khan RI, Wise RA, Fozard JL. Determinants of maximal inspiratory pressure. The Baltimore Longitudinal Study of Aging. Am J Respir Crit Care Med. 1998;158(5 Pt 1):1459-64. PMid:9817693. http://dx.doi.org/10.1164/ ajrccm.158.5.9712006

14. Patterson SL, Forrester LVV, Rodgers MM, Ryan AS, Ivey FM, Sorkin JD, et al. Determinants of walking function after stroke: Differences by deficit severity. Arch Phys Med Rehabil. 2007;88:115-119. PMid:17207686. http://dx.doi.org/10.1016/j.apmr.2006.10.025

15. Mukherjee D, Patil CG. Epidemiology and the global burden of stroke. World Neurosurg. 2011;76(6 Suppl):S85-90. PMid:22182277. http://dx.doi. org/10.1016/j.wneu.2011.07.023

16. Folstein MF, Folstein SE, McHugh PR. "Mini-mental state": A practical method for grading the cognitive state of patients for the clinician. J Psychiatr Res. 1975;12:189-98. http://dx.doi.org/10.1016/0022-3956(75)90026-6

17. Brucki SMD, Nitrini R, Caramelli P, Bertolucci PHF, Okamoto IH. Sugestões para o uso do mini-exame do estado mental no Brasil. Arq Neuropsiquiatr. 2003;61(3B):77781. PMid:14595482. http://dx.doi.org/10.1590/ S0004-282X2003000500014

18. Souza AC, Magalhaes LC, Teixeira-Salmela LF. Adaptação transcultural e análise das propriedades psicométricas da versão brasileira do Perfil de Atividade Humana. Cad Saude Publica. 2006; 22(12):2623-2636. PMid:17096041. http://dx.doi.org/10.1590/S0102-311X2006001200012

19. Davidson M, De MN. A systematic review of the Human Activity Profile. Clin Rehabil. 2007;21(2):151162 . PMid:17264109. http://dx.doi. org/10.1177/0269215506069475 
20. Dempster WJ. Space requirements of the seated operator. Wright Patterson Air Force Base; 1985. (Rep. No. WADC-TR-tt-159).

21. Sharp SA, Brouwer BJ. Isokinetic strength training of the hemiparetic knee: Effects of function and spasticity. Arch Phys Med Rehabil. 1997;78:1231-36. http://dx.doi. org/10.1016/S0003-9993(97)90337-3

22. Guyatt GH, Thompson PJ, Berman LB, Sullivan MJ, Townsend M, Jones NL, et al. How should we measure function in patients with chronic heart and lung disease? J Chronic Dis. 1985;38(6):517-24. http://dx.doi. org/10.1016/0021-9681(85)90035-9

23. Iwama AM, Andrade GN, Shima P, Tanni SE, Godoy I, Dourado VZ. The six-minute walk test and body weightwalk distance product in healthy Brazilian subjects. Braz J Med Biol Res. 2009;42(11):1080-5. PMid:19802464. http://dx.doi.org/10.1590/S0100-879X2009005000032

24. Soares MR, Pereira CAC. Six-minute walk test: Reference values for healthy adults in Brazil. J Bras Pneumol. 2011;37(5):576-583.

25. ATS Committee on Proficiency Standards for Clinical Pulmonary Function Laboratories. ATS Statement: Guideline for the six-minute walk test. Am J Respir Crit Care Med. 2002;166:111-7. PMid:12091180. http://dx.doi. org/10.1164/ajrccm.166.1.at1102

26. Britto RR, Sousa LAP. Six minute walk test: A Brazilian Standardization. Fisioter Mov. 2006; 18(4):49-54.

27. Neder JA, Andreoni S, Lerario MC, Nery LE. Reference values for lung function tests. II: Maximal respiratory pressures and voluntary ventilation. Braz J Med Biol Res. 1999;32:719-27. PMid:10412550. http://dx.doi. org/10.1590/S0100-879X1999000600007

28. Souza RB. Pressões respiratórias estáticas máximas. J Pneumol. 2002;28 Suppl 3:S155-65.

29. Hamnegard CH, Wragg S, Kyroussis D, Aquilina R, Moxham J, Green M. Portable measurement of maximum mouth pressures. Eur Respir J. 1994;7:398401. PMid:8162993. http://dx.doi.org/10.1183/0903193 6.94.07020398

30. McConnell AK, Copestake AJ. Maximum static respiratory pressuresinhealthy men and women: Issues of reproducibility and interpretation. Respiration. 1999;66:251-8. http:// dx.doi.org/10.1159/000029386

31. Portney LG, Watkins MP. Foundations of Clinical Research: Applications to practice. 3rd ed. Upper Saddle River: Prentice-Hall; 2008.

32. Sutbeyaz ST, Koseoglu F, Inan L, Coskun O. Respiratory muscle training improves cardiopulmonary function and exercise tolerance in subjects with subacute stroke: A randomized controlled trial. Clin Rehabil. 2010;24(3):240-50. PMid:20156979. http:// dx.doi.org/10.1177/0269215509358932

33. Alon G. Defining and measuring residual deficits of the upper extremity following stroke: A new perspective.
Top Stroke Rehabil. 2009;16(3):167-76. PMid:19632961. http://dx.doi.org/10.1310/tsr1603-167

34. Adams RW, Gandevia SC, Skuse NF. The distribution of muscle weakness in upper motoneuron lesions affecting the lower limb. Brain. 1990;113(5):1459-76. PMid:2245306. http://dx.doi.org/10.1093/brain/113.5.1459

35. Dombovy M. Stroke: Clinical course and neurophysiologic mechanism of recovery. Phys Rehabil Med. 1991;2:171-88.

36. Teixeira-Salmela LF, Devaraj R, Olney SJ. Validation of the human activity profile in stroke: A comparison of observed, proxy and self-reported scores. Disabil Rehabil. 2007;29(19):1518-24. PMid:17852225. http:// dx.doi.org/10.1080/09638280601055733

37. Brincks J, Nielsen JF. Increased power generation in impaired lower extremities correlated with changes in walking speeds in sub-acute stroke patients. Clin Biomech. 2012;27(2):138-44. PMid:21899933. http:// dx.doi.org/10.1016/j.clinbiomech.2011.08.007

38. Bohannon RW, Bubela DJ, Wang Y, Magasi SR, Gershon RC. Adequacy of belt-stabilized testing of knee extension strength. J Strength Cond Res. 2011;25(7):1963-67. PMid:21399535 PMCid:PMC3116990. http://dx.doi. org/10.1519/JSC.0b013e3181e4f5ce

39. Hanten WP, Ramberg CL. Effect of stabilization on maximal isokinetic torque of the quadriceps femoris muscle during concentric and eccentric contractions. Phys Ther. 1988;68(2):219-22. PMid:3340660.

40. Hart DL, Stobbe TJ, Till CW, Plummer RW. Effect of trunk stabilization on quadriceps femoris muscle torque. Phys Ther. 1984;64:1375-80. PMid:6473518.

41. Brown LE, Weir JP. ASEP procedures recommendation I: Accurate assessment of muscular strength and power. JEP. 2001;4(3):1-21.

42. Sezer N, Ordu NK, Sutbeyaz ST, Koseoglu BF. Cardiopulmonary and metabolic responses to maximum exercise and aerobic capacity in hemiplegic patients. Funct Neurol. 2004;19(4):233-8. PMid:15776791.

43. Pires SR, Oliveira AC, Parreira VF, Britto RR. Teste de caminhada de seis minutos em diferentes faixas etárias e índices de massa corporal. Rev Bras Fisioter 2007;11(2):147-51. http://dx.doi.org/10.1590/ S1413-35552007000200010

\section{Correspondence}

\section{Luci Fuscaldi Teixeira-Salmela}

Universidade Federal de Minas Gerais

Departamento de Fisioterapia

Av. Antônio Carlos, 6627, Campus Pampulha CEP 31270-901, Belo Horizonte, MG, Brasil

e-mail: lfts@ufmg.br, janainepolese@yahoo.com.br 